\title{
Massive hemobilia during endoscopic retrograde cholangiopancreatography in a patient with chol- angiocarcinoma: a case report
}
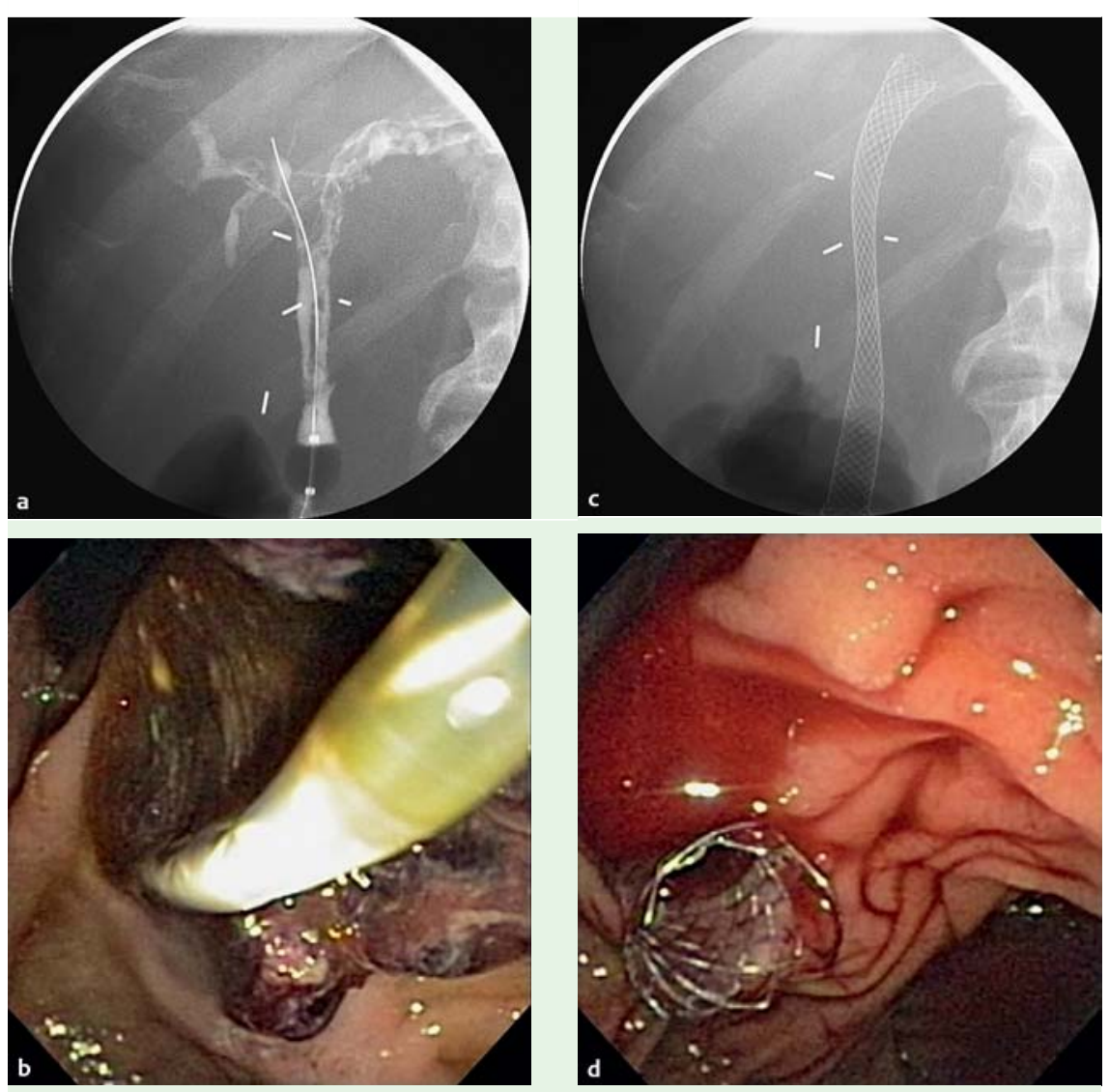

Fig. 1 a Fluoroscopic visualization of clots in the biliary tree. Also note the presence of a hilar shadow suggestive of cholangiocarcinoma. b Clots being extracted from the biliary tree using the balloon catheter. c SEMS in situ, fluoroscopic image. d Distal end of the SEMS visible at the ampulla.

A 65 year old gentleman with a diagnosis of cholangiocarcinoma and previously placed Cotton-Leung intrahepatic biliary ductal stents, admitted with symptoms suggestive of biliary obstruction and cholangitis, underwent urgent endoscopic retrograde cholangiopancreatography (ERCP) ( $\bullet$ Fig. 1 a).

After removing the previously placed stents, large clots and pus were extracted using a balloon catheter (BC) ( $\bullet$ Fig. 1 b), following which massive bright red bleeding was observed along with systemic hypotension and tachycardia.

Intravenous fluid resuscitation was initiated, and the $\mathrm{BC}$ was re-inserted into the distal common bile duct (CBD), inflated and left in-situ for 15 minutes to provide tamponade. The patient responded well to intravenous fluids. Upon deflation of the balloon, it was observed that bleeding had stopped. A fully-covered self-expanding metal stent (SEMS) was introduced into the $\mathrm{CBD}$, extending down from the left side of the hilar bifurcation ( $\bullet$ Fig. 1 c, d). No further bleeding or biliary obstruction was noted until surgical resection 3 weeks later, at which time the stent was easily removed.

First-line intervention for severe hemobilia is widely accepted to be angiographic embolization of the feeder vessel, with less preferred alternatives being surgical ligation of the bleeding vessels, or, as a last resort, segmental hepatic resection $[1,2]$. Using the $\mathrm{BC}$ for tamponade is an effective temporary measure. The constant radial expansile force of a fully-covered SEMS makes it a potential long-term tamponade device while simultaneously providing biliary drainage [3]. Close monitoring is required initially to ensure the patient is not continuing to bleed along the sides of the stent. To the best of our knowledge only two other reports have previously described a similar procedure $[4,5]$. We propose that emergent use of a fully-covered SEMS should be considered a viable first-line measure that may obviate the need for angiography or surgical intervention in patients experiencing massive hemobilia while undergoing ERCP.

\section{Endoscopy_UCTN_Code_CPL_1AK_2AD}

Competing interests: None

\section{P. Bagla, T. Erim, T. M. Berzin, \\ R. Chuttani.}

Division of Gastroenterology, Beth Israel Deaconess Medical Center and Harvard Medical School, Boston

\section{References:}

1 Green MHA, Duell RM, Johnson CD et al. Haemobilia. Br J Surg 2001; 88: 773 - 786

2 Nicholson T, Travis S, Ettles D et al. Hepatic artery angiography and embolization for hemobilia following laparoscopic cholecystectomy. Cardiovasc Intervent Radiol 1999; 22: $20-24$

3 Isayama $\mathrm{H}$, Nakai $Y$, Togawa $O$ et al. Covered metallic stents in the management of malignant and benign pancreatobiliary strictures. J Hepatobiliary Pancreat Surg 2009; 16: 624-627

4 Rerknimitr R, Kongkam P, Kullavanijaya P. Treatment of tumor associated hemobilia with partially covered metallic stent. Endoscopy 2007; 39 (Suppl 1): 225

5 Layec S, D'Halluin PN, Pagenault $M$ et al. Massive hemobilia during extraction of a covered self-expandable metal stent in a patient with portal hypertensive biliopathy. Gastrointest Endosc 2009; 70: 555 -556

Bibliography

DOI $10.1055 / \mathrm{s}-0030-1255923$

Endoscopy 2012; 44: E1

(c) Georg Thieme Verlag KG Stuttgart · New York . ISSN 0013-726X

\section{Corresponding author}

\section{Tolga Erim, D. 0 .}

Division of Gastroenterology

Beth Israel Deaconess Medical Center and Harvard Medical School

330 Brookline Avenue, Boston

MA 02215, USA

Fax: 617-667-2767

terim@bidmc.harvard.edu 